\title{
Moderation Movement in Iran; Moving between Liberalism and Religious Intellectualism
}

\author{
Ansar Amini \\ Department of Politics and International Relations, Islamic Azad University \\ Central Tehran Branch, Tehran, Iran \\ Corresponding Email: ali.seidi@yahoo.com \\ Amir Hossein Mosaver Rahmani \\ Department of Politics and International Relations, Islamic Azad University \\ Central Tehran Branch, Tehran, Iran
}

Received: December 20, 2015 Accepted: January 13, 2016 Published: February 28, 2016

doi:10.5296/jsr.v7i1.8757 URL: http://dx.doi.org/10.5296/jsr.v7i1.8757

\begin{abstract}
If we consider the moderation movement as a political method, this method can get help from other thoughts and discourses for reaching its desired goal. Accordingly, it seems that this movement can be defined as a thought derived from two discourses. One of them, as the dominant discourse in the global system, is called liberalism and its tolerance and moderation can be observed from John Rawls's political thought to recent thinkers like John Walls and social righteousness discourse and the proponents of liberal democracy. The other discourse, religious intellectualism in Iran, has emphasized the need for reforms, tolerance, moderation and avoidance of extremes after 1982s. Nowadays it seems that there is no country which does not benefit from the parameters of liberalism like human rights' discourse, democracy, tolerance, secularism, supporting the rule of law, etc. in its slogans and policies. On the other hand, religious intellectualism in Iran, as a known movement from previous decades up to now, has made an attempt to reconcile religion with the modern world and its political thought is based on such concepts as democracy, tolerance, human rights, spiritual wisdom, etc. This paper aimed to completely describe the main concepts of liberalism as a political philosophy and then religious intellectualism in Iran and reach a comprehensive view of the political thought in the moderation movement. Accordingly, the main question of the study can be posed as "to what extent can the moderation movement be influenced by other discourses dominant in the global system (liberalism) and the religious intellectualism movement?" Undoubtedly, in this study we do not intend to prove that liberalism and
\end{abstract}


religious intellectualism or moderation are the same and the discussion and arguments made in this paper are in line with the effects that moderation has received from external (liberalism) and internal (religious intellectualism) sources. Descriptive-analytic and descriptive-historical methods were used for this purpose.

Keywords: Liberalism, Religious intellectualism, Moderation

\section{Introduction}

The present study hypothesizes that moderation gets help from some of the key words of liberalism and religious intellectualism and it has used the thoughts of the two above-mentioned discourses in spite of the differences that exist between them because it is supposed any thought has some key words to introduce itself. Accordingly, in this paper, the researcher has examined and analyzed keywords like moderation, tolerance, democracy, etc. to better understand the relationship among discourse thoughts.

The study analyzed religious intellectualism, particularly in the late 1980s until today. The moderation is the name of new state in Iran that came it after presidential election of 2013.This topic has been selected to indicate that moderation movement can also use the recognition of other thoughts' experiences to bring up its thought. For the moderation to come true, this attitude helps to take into account the weaknesses and correct functions of other thoughts. Because we know the moderation as a method to rule, the source of such thought should be better rooted in the deep and capable logic.

\section{Liberalism's Political Thought}

After the collapse of the communist regime in the late 1980s, political-mental system of the world was divided into two parts after the Second World War. It was liberalism that declared its domination over other thoughts. At the end of the same decade, Fukuyama wrote his famous paper "The end of history and the last man" and named liberalism as the latest and topmost of human history: the thought for happiness of humanity (Fukuyama,1992). However, neglecting the differences in ideas and criticism, we should admit that there is no country which do not benefit from parameters of liberalism like, human rights' discourse, democracy, tolerance, secularism, supporting rule of law, etc. in its slogans and policies.

One issue to be noticed regarding the categorizing of principles and liberalism's values is the interpretation of liberalism's characteristics. Different authors have pointed out various points in this respect. In this paper we express the totality of Kekes division and anything considered as liberalism's features by different authors and scholars. Generally, Kekes believes that the main values of liberalism are: $\mathrm{A}$, pluralism $\mathrm{B}$, freedom $\mathrm{C}$, rights $\mathrm{D}$, equality $\mathrm{E}$, and righteousness. Accordingly, if pluralism accepts the condition that there are values and many various interpretation of happiness for life so, freedom is the political situation which individuals can select among these values and interpretations. Freedom in its political sense regarding these two terms is equal to the idea that the citizens of a society must be allowed to select the values and interpretation of lifetime happiness without interference of others 
(Kekes, 1998). So, we can consider freedom as an aim which is achievable and selecting it by a person or a citizen of the society is not prevented by the interference of others.

This freedom can be defined in a pluralist society in which the person as humankind with the consciousness along with others has the authority to express ideas about his primary, social, and political rights. This significant matter is provided by tolerance and moderation which are the other principle of liberalism. John Lock (one of the pioneers in liberalism) propounded (the Tolerance) discussion in $17^{\text {th }}$ centaury of a philosophy perspective which provided a quite new perspective to analyzing (Righteousness) and (political moderation). It can be said that moderation and tolerance are the duties of government, social and individuals which do not allow the interference in others' activities and ideas, although they are not accepted or approved. Of course as far as these ideas and activities do not overstep others' equal rights (Arblaster, 1999). In fact the warning for avoidance in overstepping any individual's right in a liberal society can be defined in parallel with any individual's rights which is one of the other parameters of liberalism. As a matter of fact, the position of human rights in international liberalism's theory is based on the moral theory of Emanuel Kant which builds upon the cognition that moral observers oblige the practical wisdom to accept moral human rights principle (Brey, 1973).

The reason is that in liberalism's definition of a democratic society, any person has an equal right to vote. Accordingly, in this system people's governance "can be performed efficiently only when the majority of citizens have a common direct and indirect right in social decisions" (Bobio; 1998; pp. 57-58). It might be said that John Rawls's theory about political righteousness and individuals equal rights in a liberal society is more famous than the other liberal scholars. Rawls believes that in a liberal society individuals must use the facilities provided by the society equally, and called this opportunity "Primary Goods" which includes income, wealth, proper political and social education, economical and occupational opportunities, and other social benefits. In fact Rawls is willing to have moderation in "Primary Goods" division, in which fairness and justice make it possible to give all the individuals in the society equal opportunities and rights. Rationality is one of the other liberalism's features. Defending liberalism by freedom has a close relationship with belief in wisdom and rationality.

The main roots of liberalism can be found in disputations of enlightenment philosophy about arts, sciences, and the nature of development and mind and its consequences for politics in $18^{\text {th }}$ century(Rutledge: 1998). In this way, enlightenment and rationality are presented as a campaign to support freedom and wisdom in contrast to the dogmatism of tradition and uncivilized consequences in west civilization and culture and in this perspective tolerance and moderation are made possible in the shadow of judgment of wisdom against various perspective of the society.

\section{Religious Intellectualism in Iran}

There are many disagreements for the definition of religious intellectualism but it can be considered as a movement to reconciliation and the relationship between religion and custom with modern world. This idea developed in Muslim countries about one hundred years ago. In 
Iran, the term religious elitism was first put forward by Dr. Ali Shariati. Before presenting this issue by Shariati, the mainstream of religious elitism in Iran existed in different forms. Ali Shariati stated that religious elitism should be open-minded with understanding of his society, his history and his culture (Amini, 2014).

With regard to the totality of these thinkers' thought, it can be said that since these thinkers believed that intellectualism depends on social changes and made an effort to solve retardation problems of Islamic societies, they have been called "region's intellectuals" (Wikipedia, Azad university). In fact in an overall perspective it can be said that nowadays the main efforts of region's intellectuals group is to clarify whether it is possible to be pious and democratic simultaneously and respect "human rights" (Dabagh; 2013).

\section{Political Thought of Religious Intellectualists}

It can be said that after the revolution religious intellectualism established a new discourse which is a proper and green discourse for the settlement era, against red discourse which was suitable for the establishment and revolution era (Soroush, 2001). In this regard, they categorize human rights as a meaningful principle, in accordance to freedom and one of the democratic bases and emphasize both of them. "Firstly, it is only through democracy that human rights as freedom rights can find its specific contents and themes in new era" (Shabesrari, 2001, p. 225). Then, for the logic of some principles of human rights which are non-religious this reasoning has presented that current freedoms in human rights are human freedom against human and it does not mean God's accepting or rejecting of humans' humanity has an equal result for the God(Shabesrari, 2003).

They connect faith's concept with freedom. Faith is given only to those who are ready to accept it, and only those who have free thought and free volition are ready for such an acceptance (Shabesrari, 1997). Generally, according to religious intellectualism opinion, faith means accepting religion's experiences especially Islam and the history in which these experiences have happened. And also in definition of freedom it should be indicated that" man will be free from what, in what and for what goal until these three affairs would not be clarified the meaning of freedom will not be made clear" (Shabestari, 1997, p. 32). And of course, freedom will consolidate by abiding ethics and morality in society. Because the limitations for freedom of expression are the avoidance to harm others, it means compliance with ethical issues and respect for public morals (Kadivar, 2009). In this case, freedom's boundary should be specified so far as to define any person's duty and authority, in other words disorder and anarchy do not rule in society. In this respect, freedom and law are put together to maintain order in society.

To found law in society, religious intellectuals emphasize the separation of the powers. According to their belief, the society which claims the separation of powers should reach understanding in three categories of rights; the triple freedoms' rights, civil rights, and social rights. When these rights have been proposed and people are considered as citizens and every individual of the society has an equal right, then this question will arises that if political power is in the control of one person, will it not be abused?"(Shabestari, 2003, p.521), and this is one of the reasons that religious intellectuals prefer democracy to other ruling methods. 
According to their belief, the difference between democracy and other ruling forms is that a democratic government can deprive the society which encompasses different groups and populations from the power and the major guarantee of this situation is that the government is liable to obey the legal regulations which exist in society in order to protect freedom of organizations and to express opposing beliefs and theories (Shabestari, 2003). In this case, the pluralism of ideas and beliefs arises in the society and in a pluralistic society, individuals can live with each other with different ideas and this plurality can exist in religion domain as well. "It is because those who believe in cultural and religious pluralism cannot neglect social pluralism" (Soroush, 2002, p. 1) and in this regard, tolerance and forbearance can be defined. As a result, religious intellectuals in their view to moderation, and prevention from excess and negligence, define forbearance as follow" respecting others' political and social rights which has been accepted as possible. All humans, from the perspective that they are human beings, have equal rights whilst they may have different opinions, morals, actions, and even different religious beliefs"(Shabestari, 2003, p.77).

Rationality is the point which should be accepted along with tolerance in different ideas and thoughts. In fact, in a society in which the groups' emotions and prejudices are dominated, tolerance, freedom and law cannot come into existence and have no meaning. Religious intellectuals emphasizes that rationality paves the way for tolerance and pays attention to others. Rational biome is "fragile" and" feeble". To develop moderation in the Islamic world, an attempt should be made to strengthen rational biome (Paya, 2013). Rationality in discourse and manner are communicative instruments in modern world. Rationality along with freedom can certainly be of two parameters for modernity; one of them is to respect human rationality and the other one is to respect his freedom suffice to value the modernistic perspective towards the universe and human beings in spite of its weaknesses and shortcomings.

\section{The Moderation Movement}

President Hassan Rouhani introduced the moderation movement. He after presidential election of 2013 in IRAN sad, I am moderation. Its mean he is not radical in his opinions (No left policy movement and no right policy movement). We have to say about the moderation basics and its background in Iran and his thought for grow it.

Two projects started in the late 1980s and the early 1990s, Dr. Soroush and his colleagues' religious intellectualism and Hashemi Rafsanjani economical development, respectively (Hajarian, 2013). It can be said that through these two projects renovation of political reforms (in $7^{\text {th }}$ and $8^{\text {th }}$ governments) has emerged in later years. Political reconstruction of $1990 \mathrm{~s}$ in Iran extremely influenced conventional religious intellectualism's atmosphere. The construction era (1990-1998) and Iranian government officials' approach to free economy and entrance of bureaucrat and technocrats to government and setting aside ideological forces (and revolutionists) have prepared a suitable ground for presenting a new interpretation of religion, and the victory of reformation (movement) in May,2nd,1998 which itself has come from conventional religious intellectualism's approaches, indicates the influential atmospheres which this movement had with social conditions in 1991s in Iran (Nejadiran, 2007; 2006). 
In fact the overlap between these two movements, religious intellectualism and reformation movement, in which the first one had a formative view to religious thought and social-political construction and the later was a practical policy in the country with a religious regime caused religious intellectualism to present its political thoughts more than before. In this regard,(after the victory of reformative in May,2nd,1998) neo religious intellectualisms tried to coordinate with human rights, freedom, and modern harmonistic views and the tolerance and freedom increased in their thought. We interpret this mental-political relation between religious intellectualism and reformation movement as adaptive brothers. So, according to adaptive brotherhood reasoning of religious intellectualism, we should consider the principles of reformation thought with reformation movement and then reach political moderation thought in reformation. "In reformation, the emphasis is on fundamental freedoms in society and supporting it, and defending people's governance right about their fate".

Obviously this attitude should emphasize moderation view in reformation and reject excessiveness and negligence (Katami, Bita). It can be concluded that reformation emphasize the view that compatibility of civil society is not possible with revolution and its leaping movements. We do not want to make a revolution, because if it is even possible the result will be the same after a few years or decades with the position that we are engaging now (Khatami, 2013). So reforms movement is the rational criticism of some of the affairs and pursuant to moderation and is looking for a pathway for reformation of some of the governmental problems. Accordingly, it can be said that political moderation method is confirmative with political reformation method. Reformation and moderation policy have a specific attention to rationalism, so the rationality of reformations is influenced by instrumental and scientific rationality but the rationality of the moderation is broader (Jalalipour, 2013). The issue of instrumental rationality in reformation can be defined in an effort to political development and internalizing of collective wisdom instead of extremeness and negligence, although it emphasizes collective wisdom, and it has not been defined yet as well and it will be meaningful with other parameters.

President Rouhani has presented the parameters of moderation as follow: Moderation emphasizes on tolerance and morals. The government of Prudence and Hope will emphasize on the rule of law, observance of the rights and freedom of all of the citizens, accountability to the society and scientific administration. People wish to be respected; they want to live in a free, moral, and intellectual situation. Moderation is avoiding excessiveness and negligence, balance between aspiration and reality, and preferring national interests over partisan and factional interests, national consensus, obeying the law and the distance of tolerance to Political interactions, reducing fantasy and hallucination, concentration on thinking, planning, clearness, and using expertise.

So by this definition, it should be said that moderation is meaningful with other parameters like law, freedom, tolerance, political interactions, national consensus, civil rights, democracy, and accountability to the society. Otherwise, the right of expressing of one's existence or a citizen who is demanding an expectation has no meaning. According to this reasoning, we can define moderation and rationality as an opportunity to hear the expectation of opinions 
and different thoughts and accepting a balanced side to avoid excessiveness and negligence. And it can be concluded that moderation cannot change as a power to maintain status quo in order to implement the mentioned parallels to make some reforms in society. One of these reforms is civil rights (ownership rights, social rights, and other rights and freedom's accordance based on the third paragraph of Constitution).

In this regard, the president proposes civil rights, justice, and equality and is aware of tribal and thoughts' diversity. And he believes that in civil rights men and women, Kurd, Turk, Arab and Persian are equal" (Rouhani's speech in June 2013) and believes that "the sufficient level of people's demands about civil rights have not been provided adequately yet (Rouhani, Julay, 2013). Certainly, these rights are practical in a society in which the vote and people's ideas influence the ruling and government decisions. So this question will be posed that "how can we achieve tolerance and civil rights in a society with a religious rule and a variety of thoughts and religions? And the response is "The Government believes that the religious beliefs should promote without imposition and obligation and it should take place through the path to improve the religious living conditions on the circuit of rationalism and Islam" (Rouhani, Julay, 2013).

So, moderation movement presents a form of governing (religious democracy) to accomplish its political and religious-cultural beliefs. Since the president considers people's high participation in election, and declaring of candidates' slogans and polices, the huge analysis and criticisms on election, etc. (Rouhani; July, 2013) as this kind of ruling. But in religious democracy, to what extent the government can rely on the votes and beliefs of its citizens? Indeed, the relying of state on people means that the state respects people's expectation, public opinions, public and collective actions (Rouhani, July, 2013). In fact the public participation is considered as a value and freedom, equality and righteousness will be understood. This policy can actually be viewed through intellectual and wisdom process.

Free thinking, freedom, the freedom to criticize and expand knowledge leads into a society with political health (Rouhani, July, 2013) and this will be possible by moderation in insight and the rights of opposites to declare their views. The summery of above discussion indicates that in a democratic society, freedom, in its general meaning, is considered as public righteousness and the criticizing opportunity causes intellectual leap and collective wisdom in the society. Of course, the criticisms is that "moderation is not to deviate from the principles" (Rouhani; inauguration ceremony: July, 2013) because moderation believes in the principles of law as "appropriate governance" which is feasible in priority of law:

"Appropriate governance includes the rule of law, respecting peoples' civil freedom and rights, accountability to the society, clearness in administration and declaring information, considering people's rights, and guarantee people's ineffectual participation in their fate which is a respectable ideal in mankind society" (Rouhani; July, 2013).

\section{Conclusion}

It was mentioned that liberalism has achieved its former power after 1998 and developed its principles much more than before. Advocating from democracy that is happening in many 
countries is not accidental; liberalism has also expanded other principles in processing its thought. The keywords for presenting liberalism are freedom, human rights, tolerance in discourse, action, righteousness, etc. However, in this paper we considered religious intellectualism and suggested that the mentioned movement was an effort to direct our society to development and recognition of communicative instruments in the modern world. Religious intellectualism has tried and will reconcile religion with modernism and as was mentioned it could influence Instrumental rationality.

Surely, it was reformation government that has proposed political modernization. In the meantime, the researcher has achieved the moderation movement by determining the keywords of religious intellectualism and reformation movement. The extents to which the moderation can continue religious-political trend of modernization certainly lead to the result that in the compatibility between the former movement and moderation. Two points should be noticed here: First, moderation raised as a government-intellectual movement in an Islamic state; Second, moderation is trying to reform the society which is possible with parameters like democracy, obeying the law, separation of powers, etc. and determines the significance of moderation and religious intellectualism. But we should notice that moderation has also other parameters like Secularism and reliance on intellectualism. Certainly some of the thinkers have shown their interests on these beliefs. So, our aim in moderation was those concepts which have influenced moderation and are more common in their thought. Perhaps religious intellectualism is rejected in liberalism. In this regard, religious intellectualism emphasizes more on religious culture, faith, and spiritual wisdom among elite group than religious rule.

\section{References}

Amini, A. (2014). The Effects of Liberalism on Iranian Religious

Intellectualism: Case of MojtahedShabestari. International Journal of

Research in Social Sciences, Volume-4, Issue-2, pp 1-12.

Arblaster, A. (1999). The rise and decline of western liberalism. Oxford: Basil

Blackwell.

Bobbio, N. (1998).Liberalism and democracy. London: Verso Press.

Brey. J. F. (1973). Social philosophy. New Jersey: Prentice Hall.

Dabagh, S. (2013).The share of mind, share of heart.Mehrnameh Special Issue,

20, 284-290.

Fukuyama, F. (1992). The end of history and last man. London: Hamish

Hailton.

Hajarian, S. (2013). Interview with the Dynamic Thought magazine. 
Jalalipour, H. R. (2013). National conference on establishing the concept of moderation at a glance. Tehran: Iran.

Kadivar, M. (2009). Which theocracy? What freedom? Proceedings of religion and freedom. Tehran: Zekr Institute of publishing and research.

Kekes, J. (1998). Against liberalism.Ithaca: Cornell University Press.

Khatami, M. R. (2013). Islam criticizes liberalism and rejects Fascism. Isna News, Tehran.

Nejadiran, M. (2007). Religious enlightenment and modernity in Iran.

Unpublished M.A. thesis, faculty of political science, Islamic Azad University, Central Tehran Branch, Tehran, Iran.

Paya, A. (2013). Philosophical review of moderation in Islamic and Western thought. Tehran: Dana News.

Rouhani, H. (2013a). The possibility of moderation! Media Horizon Conference, Tehran, Iran.

Rouhani, H. (2013b). Speech in ShahidShirudi stadium. Tehran, Iran.

Rouhani, H. (2013c). Speech in Ahvaz. Ahvaz, Iran.

Rutledge, Encyclopedia of Philosophy (1998). General Editor Edward Craig. London and New York: Rutledge.

Shabestari, M. (1997). Faith and freedom. Tehran: New Project.

Shabestari, M. (2001). Critique of the official reading of religion. Tehran: New Project.

Shabestari, M. (2003). Hermeneutics, book, and tradition. Tehran: New Project.

Soroush, A. (2001). Direct path. Tehran: Cultural Institute of Path.

Soroush, A. (2002). The concept of theocracy (Proceedings of religion and state). Rasa Press. 